\title{
Three-Step, "One-Pot" Radiosynthesis of 6-Fluoro-3,4-Dihydroxy-L-Phenylalanine by Isotopic Exchange
}

Franziska M. Wagner, Johannes Ermert, and Heinz H. Coenen

Institut für Neurowissenschaften und Medizin, INM-5: Nuklearchemie, Forschungszentrum Jülich GmbH, Jülich, Germany

The ${ }^{18} \mathrm{~F}$-labeled aromatic amino acid 6-fluoro-3,4-dihydroxy-Lphenylalanine $\left(6-{ }^{18} \mathrm{~F}-\right.$ fluoro-L-DOPA) is widely used as a radiopharmaceutical in neurologic and oncologic PET. In this study, a novel approach to the preparation of carrier-added (CA) $6-{ }^{18}$ F-fluoro-L-DOPA in 3 radiosynthesis steps was developed and evaluated; in this approach, direct nucleophilic ${ }^{18} \mathrm{~F}$ fluorination of a protected amino acid derivative was used. The method currently used for the routine preparation of $6-{ }^{18} \mathrm{~F}$-fluoro-L-DOPA by electrophilic labeling is limited to the production of small amounts of activity at high costs. Alternative syntheses based on the advantage of large-scale production of nucleophilic ${ }^{18} \mathrm{~F}$-fluoride, however, either have resulted in insufficient enantiomeric purity or are difficult to automate because of the complexity of the necessary multiple steps. Methods: An isotopic exchange reaction on the precursor $(2 S, 5 S)$-tert-butyl5-(4-benzyloxy-2-fluoro-5-formylbenzyl)-2-tert-butyl-3-methyl-4oxoimidazolidine-1-carboxylate was used. The formyl group served as the activating group in the ${ }^{18} \mathrm{~F}$-for- ${ }^{19} \mathrm{~F}$ exchange with tetrabutylammonium bicarbonate for anion activation in $\mathrm{N}, \mathrm{N}$-dimethylformamide. The intermediate was converted to a hydroxy group by Baeyer-Villiger oxidation with meta-chloroperbenzoic acid. After final deprotection with hydrobromic acid, CA 6- ${ }^{18} \mathrm{~F}$-fluoro-L-DOPA was isolated by high-performance liquid chromatography. Results: The precursor was obtained by an 11 -step organic synthesis. The optimized isotopic ${ }^{18} \mathrm{~F}$ exchange proceeded with a radiochemical yield of about $50 \%$. The complete preparation and isolation of CA $6-{ }^{18} \mathrm{~F}$-fluoro-L-DOPA thus far are possible with a radiochemical yield of about $22 \%$, within a synthesis time of $105 \mathrm{~min}$, and at a much higher specific activity than with the electrophilic method. The enantiomeric excess of the desired L-isomer was greater than 96\%.Conclusion: The pathway to $6-{ }^{18} \mathrm{~F}$-fluoro-L-DOPA by isotopic exchange not only is more efficient but also is suited to automation as a "one-pot" procedure.

Key Words: radiochemistry; radiopharmaceuticals; 6-18F-fluoroL-DOPA; radiosynthesis

J Nucl Med 2009; 50:1724-1729

DOI: 10.2967/jnumed.109.063297

Received Feb. 13, 2009; revision accepted Jul. 10, 2009. For correspondence or reprints contact: Johannes Ermert, Institut für Neurowissenschaften und Medizin, INM-5: Nuklearchemie, Forschungszentrum Jülich GmbH, D-52425 Jülich, Germany. E-mail: J.Ermert@fz-juelich.de

COPYRIGHT $\odot 2009$ by the Society of Nuclear Medicine, Inc.
A n ${ }^{18}$ F-labeled analog of 3,4-dihydroxy-L-phenylalanine, $\quad{ }^{18}{ }^{18} \mathrm{~F}-$ fluoro-3,4-dihydroxy-L-phenylalanine $\left(6-{ }^{18} \mathrm{~F}-\right.$ fluoro-L-DOPA), is an established radiotracer for diagnosis of the integrity and function of the nigrostriatal dopaminergic system by PET $(1,2)$. More recently, it was also found that $6-{ }^{18} \mathrm{~F}$-fluoro-L-DOPA has potential for oncologic diagnosis $(3,4)$, especially in PET studies of neuroendocrine tumors (5).

Because $6-{ }^{18} \mathrm{~F}$-fluoro-L-DOPA can be applied in a carrieradded (CA) form (6), the commonly used method for its routine preparation is the electrophilic fluorodestannylation reaction $(7,8)$, for which remote-controlled synthesis units are commercially available $(9,10)$. Nevertheless, the electrophilic method is limited to the production of small amounts of activity at high costs, even when the ${ }^{18} \mathrm{O}(\mathrm{p}, \mathrm{n}){ }^{18} \mathrm{~F}$ nuclear reaction is used (11), and only half of the radioactivity of molecular ${ }^{18} \mathrm{~F}-\mathrm{F}_{2}$ can be incorporated. Therefore, the use of this important tracer in clinical centers is limited mainly by the lack of a nucleophilic radiofluorination method based on the advantage of the large-scale production of ${ }^{18} \mathrm{~F}$-fluoride.

The first nucleophilic approaches for the radiosynthesis of $6-{ }^{18} \mathrm{~F}$-fluoro-L-DOPA were based on substitution with ${ }^{18} \mathrm{~F}$-fluoride on small benzaldehyde derivatives (12). After the ${ }^{18} \mathrm{~F}$-labeling step, the aldehyde functionality was converted to a benzyl halide group, subsequently coupled either to chiral auxiliaries (13) or to a prochiral auxiliary by chiral phase transfer alkylation (14). The latter strategy permits the large-scale production of $6-{ }^{18}$ F-fluoro-L-DOPA with excellent chemical, radiochemical, and enantiomeric purities $(>96 \%)$. Furthermore, both methods yield $6-{ }^{18} \mathrm{~F}$-fluoro-LDOPA at the no-carrier-added (NCA) level. However, because of their complexity, these multistep syntheses are cumbersome to automate.

For improving the efficiency of the nucleophilic preparation of $6-{ }^{18} \mathrm{~F}$-fluoro-L-DOPA, a direct nucleophilic isotopic exchange reaction on a formyl-activated masked aromatic amino acid derivative was studied. The required carbon skeleton and the chiral center with the desired configuration were constructed before introduction of the ${ }^{18} \mathrm{~F}$-fluoride ion by use of a homochiral piperazine derivative as described by Schöllkopf' (15). After cryptand-mediated ${ }^{18} \mathrm{~F}$ introduc- 
tion, the intermediate was transformed to $6-{ }^{18} \mathrm{~F}$-fluoro-LDOPA by Baeyer-Villiger oxidation and hydrolysis (16). This method, however, yielded $6-{ }^{18} \mathrm{~F}-$-fluoro-L-DOPA at an insufficient enantiomeric excess, only $70 \%$.

Kuroda et al. (17) described the synthesis of a similar precursor with this strategy by choosing a homochiral imidazolidinone derivative (according to Seebach et al. (18)) as the masked amino acid functionality and iodide as the leaving group in the formyl-activated ${ }^{18} \mathrm{~F}$ exchange reaction. Unfortunately, no ${ }^{18} \mathrm{~F}$-labeling results with this precursor have been reported so far. It can be presumed that the stability of the precursor is not sufficient for an ${ }^{18} \mathrm{~F}$-labeling reaction.

In the present study, the advantages of the concepts of both Tierling et al. (16) and Kuroda et al. (17) were combined in a novel, efficient nucleophilic "one-pot" approach for the preparation of $6{ }^{18} \mathrm{~F}$-fluoro-L-DOPA; with this approach, direct nucleophilic ${ }^{18} \mathrm{~F}$ fluorination of a protected chiral amino acid precursor yielded the desired product at a high enantiomeric excess.

\section{MATERIALS AND METHODS}

All chemicals were purchased from Aldrich, Merck, or KMF in pro analysi quality and were used without further purification. 6-Fluoro-L-DOPA and 6-fluoro-D,L-DOPA standards were obtained from ABX.

High-performance liquid chromatography (HPLC) separations were achieved with a Sykam S1000 pump, a Knauer K2500 UV/ VIS detector $(254 \mathrm{~nm})$, a manual Rheodyne injector (20- or 2,000$\mu \mathrm{L}$ loop), and an $\mathrm{NaI}(\mathrm{Tl})$ well-type scintillation detector (EG\&G Ortec; model 276 Photomultiplier Base) with an ACE Mate Amplifier and BIAS supply (Ortec) for radioactivity detection. Data acquisition and interpretation were performed with Nina software (Firma Nuklear Interface $\mathrm{GmbH}$ ).

\section{System A}

Analytic HPLC of ${ }^{18} \mathrm{~F}$-labeled compound $\mathbf{1 2}$ was performed with an analytic reverse-phase Kromasil $100-5 \mathrm{C}_{18}$ column $(250 \times$ $4.6 \mathrm{~mm}$; CS Chromatographieservice $\mathrm{GmbH}$ ). Elution was performed at a constant flow rate of $1 \mathrm{~mL} / \mathrm{min}$ with acetonitrile:water $(80: 20)$ (see supplemental materials [available online only at http://jnm.snmjournals.org]).

\section{System B}

Analytic HPLC of 6- ${ }^{18}$ F-fluoro-L-DOPA was performed with an analytic reverse-phase Synergi $4 \mu$ Hydro-RP 80 A column $(250 \times$ $4.6 \mathrm{~mm}$; Phenomenex). The mobile phase was aqueous acetic acid $(0.1 \%)$, and the flow rate was $1 \mathrm{~mL} / \mathrm{min}$.

\section{System C}

Preparative HPLC of $6-{ }^{18}$ F-fluoro-L-DOPA was conducted with a Synergi $4 \mu$ Hydro-RP 80 A column $(250 \times 10 \mathrm{~mm}$; Phenomenex). The mobile phase was aqueous acetic acid $(0.1 \%)$, and the flow rate was $4 \mathrm{~mL} / \mathrm{min}$.

\section{System D}

The enantiomeric purity of the radiopharmaceutical was determined after HPLC separation. A Crownpak CR (+) $5 \mu$ column $(150 \times 4 \mathrm{~mm}$; Daicel Chemical Industries) was eluted with aqueous $\mathrm{HClO}_{4}(0.02 \mathrm{M})$ at a flow rate of $1 \mathrm{~mL} / \mathrm{min}$, and ultraviolet light was monitored at a wavelength of $283 \mathrm{~nm}$.

\section{Thin-Layer Chromatography (TLC)}

In optimization studies, TLC was performed for the determination of radiochemical yields. Aluminum roll Silica Gel $60 \mathrm{~F}_{254}$ sheets (Merck) were developed with diethyl ether:petroleum ether. The ratios of the mixtures and the corresponding $\mathrm{R}_{\mathrm{f}}$ values are given later. Radioactivity on TLC plates was measured with an Instant Imager (Packard).

\section{Precursor Synthesis}

A description of precursor synthesis and analytic data, including a discussion, is available in the supplemental materials.

\section{Labeling Procedure}

Production of $\mathrm{NCA}{ }^{18} \mathrm{~F}$-Fluoride. NCA ${ }^{18} \mathrm{~F}$-fluoride was produced by the ${ }^{18} \mathrm{O}(\mathrm{p}, \mathrm{n}){ }^{18} \mathrm{~F}$ nuclear reaction with the BC 1710 cyclotron (Japan Steel Works) at Forschungszentrum Jülich as described earlier (19). The ${ }^{18}$ F-fluoride produced was purified through electrostatic adsorption on a Sigradur-Anode (HTW Hochtemperatur-Werkstoffe $\mathrm{GmbH}$ ) and desorption into $500 \mu \mathrm{L}$ of pentadistilled water (20). This solution was added to a $130-\mu \mathrm{L}$ (20- $\mu \mathrm{mol})$ solution of $0.15 \mathrm{M}$ tetrabutylammonium bicarbonate $\left(\mathrm{TBAHCO}_{3}\right)$, and the mixture was diluted with $0.9 \mathrm{~mL}$ of dry acetonitrile $(<0.03 \%$ water $)$ and transferred via syringe to a 5-mL conical vial (Reactivial; Wheaton) closed with a silicon septum. The solvent was evaporated under a stream of nitrogen at $80^{\circ} \mathrm{C}$ and 750 mbar. This azeotropic evaporation was repeated twice with $800 \mu \mathrm{L}$ of acetonitrile and was followed by evaporation of the dry Reactivial for $5 \mathrm{~min}$ at 20-30 mbar. Finally, dry tetrabutylammonium ${ }^{18} \mathrm{~F}$-fluoride was obtained as the fluorinating agent.

CA 6- ${ }^{18} \mathrm{~F}$-Fluoro-L-DOPA $\left({ }^{18} \mathrm{~F}-14\right)$. A solution of $5.7 \mathrm{mg}(11.4$ $\mu \mathrm{mol})$ of (2S,5S)-tert-butyl-5-(4-(benzyloxy)-2-fluoro-5-formylbenzyl)-2-tert-butyl-3-methyl-4-oxoimidazolidine-1-carboxylate (compound 12) in $0.8 \mathrm{~mL}$ of $\mathrm{N}, \mathrm{N}$-dimethylformamide (DMF) was added to the freshly dried residue of tetrabutylammonium ${ }^{18} \mathrm{~F}$ fluoride. The vial was then closed with a screw cap and heated at $110^{\circ} \mathrm{C}$ for $8 \mathrm{~min}$ in an oil bath. After labeling, the DMF solution was diluted with water $(9 \mathrm{~mL})$, and the entire solution was passed through a conditioned LiChrolut RP-18e (500-mg) cartridge (Merck); from this cartridge, the product $\left({ }^{18} \mathrm{~F}-12\right)$ was eluted back into the reaction vessel with $1.5 \mathrm{~mL}$ of acetonitrile. Analytic HPLC of the intermediate was performed with system A (k value, 3.15) or with TLC (ethyl acetate:petrol ether, 1:1; $\left.\mathrm{R}_{\mathrm{f}}, 0.78\right)$. The acetonitrile solution of $(2 S, 5 S)$-tert-butyl-5-(4(benzyloxy)-2- ${ }^{18}$ F-fluoro-5-formylbenzyl)-2-tert-butyl-3-methyl4-oxoimida-zolidine-1-carboxylate was azeotropically dried at $80^{\circ} \mathrm{C}$ and 800 mbar. A solution of $11 \mathrm{mg}$ of meta-chloroperbenzoic acid (mCPBA; technical grade; $77 \%$ ) in $1 \mathrm{~mL}$ of chloroform was added, and the mixture was stirred for $20 \mathrm{~min}$ at $60^{\circ} \mathrm{C}$. The intermediate compound $\left({ }^{18} \mathrm{~F}-13\right)$ was not isolated.

After chloroform was evaporated at $60^{\circ} \mathrm{C}$ and $950 \mathrm{mbar}, 1 \mathrm{~mL}$ of hydrobromic acid ( $\mathrm{HBr})(48 \%)$ was added to the residue. The vial was closed, and the solution was refluxed at $150^{\circ} \mathrm{C}$ for $30 \mathrm{~min}$. After hydrolysis, the solution was cooled and diluted with $1.0 \mathrm{~mL}$ of HPLC eluent. Finally, $6-{ }^{18} \mathrm{~F}-$ fluoro-L-DOPA $\left({ }^{18} \mathrm{~F}-14\right)$ was purified by preparative HPLC (system C; $\mathrm{k}$ value for $6-{ }^{18} \mathrm{~F}$ fluoro-L-DOPA [k value 6 -F-L-DOPA $], 1.75)$. Analytic HPLC was performed with system $B(k$ value 6 -F-L-DOPA 1.62 ) for the determination of radiochemical yields. Enantiomeric purity was analyzed with system D ( $\mathrm{k}$ value $_{6-\text { F-D-DOPA }}, 1.04$; $\mathrm{k}$ value ${ }_{6-F-L-D O P A}$, 1.65). 


\section{RESULTS}

The synthesis of $6-{ }^{18}$ F-fluoro-L-DOPA was performed in a manner similar to the 3-step procedure described by Tierling et al. (16): an ${ }^{18} \mathrm{~F}$-for- ${ }^{19} \mathrm{~F}$ displacement reaction and subsequent Baeyer-Villiger oxidation were followed by hydrolysis (Fig. 1).

In the first ${ }^{18} \mathrm{~F}$ exchange step, we observed the formation of an unwanted side product, which was identified as a decomposition product of the precursor. In order to avoid this product, we optimized the conditions of the radiofluorination reaction by systematically varying the anion activation phase transfer catalyst, solvent, temperature, and concentration of the precursor.

For optimization, initially different anion activators were studied. The standard Kryptofix 2.2.2 (Merck)/potassium carbonate system was examined with DMF as a solvent at $130^{\circ} \mathrm{C}$ to obtain information about the stability of the precursor (12) under the relatively strong basic labeling conditions. The isotopic exchange was very efficient, and after $15 \mathrm{~min}$, the sum of radiochemical yields of all ${ }^{18} \mathrm{~F}-$ labeled products formed was about $90 \%$. However, besides the desired product $\left({ }^{18} \mathrm{~F}-12\right)$, one major, as-yet-unidentified by-product (by-product A) was observed; the level of byproduct $\mathrm{A}$ increased with the reaction time. The resulting radiochemical yield of the desired product $\left({ }^{18} \mathrm{~F}-12\right)$ was thus limited to $50 \%$, as determined by TLC; by-product A exhibited an $R_{f}$ value of 0.6 (ethyl acetate:petrol ether, 1:1), and the $R_{f}$ value of ${ }^{18} \mathrm{~F}-12$ was 0.78 .

To avoid the decomposition of compound ${ }^{18} \mathrm{~F}-12$, we also used cesium carbonate and the less basic mixed Kryptofix 2.2.2/potassium oxalate and potassium carbonate (ratio, $33: 1$ ) system (21) for ${ }^{18} \mathrm{~F}$ labeling. In both cases, no byproduct was observed, but the radiochemical yield of ${ }^{18} \mathrm{~F}-12$ was less than $10 \%$. In the case of cesium carbonate for anion activation, the poor solubility of cesium carbonate in DMF was probably the reason for the relatively low radiochemical yield. With tetrabutylammonium hydroxide, the isotopic exchange was very efficient, but the unknown ${ }^{18} \mathrm{~F}$-labeled by-product A became the main product. The radiochemical yield of ${ }^{18} \mathrm{~F}-12$ amounted to only about $2 \%$. Changing the strongly basic hydroxide anion to bicarbonate led to a better relationship between the desired product $\left({ }^{18} \mathrm{~F}-12\right)$ and byproduct $\mathrm{A}$, depending on the reaction time (Table 1). On the basis of these findings, all subsequent optimizations of the nucleophilic radiofluorination reactions were performed with $\mathrm{TBAHCO}_{3}$.

The precursor was soluble in acetonitrile, DMF, dimethylacetamide (DMAA), and dimethyl sulfoxide (DMSO). The ${ }^{18} \mathrm{~F}$-labeling results obtained with acetonitrile were rather unsatisfactory, with a low yield, less than $1 \%$. With DMAA and DMSO at $120^{\circ} \mathrm{C}$, the radiochemical yield of the desired product $\left({ }^{18} \mathrm{~F}-12\right)$ was less than $30 \%$, and a further by-product (by-product B) was observed (supplemental materials). As shown in Table 2, only DMF proved to be a suitable solvent for the aromatic ${ }^{18} \mathrm{~F}$ fluorination of 12, leading to good radiochemical yields and a satisfactory relationship between the product and by-product A only.

To find the limits of the useful concentration of 12, the concentration was varied between 7.12 and $28.5 \mathrm{mmol} / \mathrm{L}$ in $\mathrm{DMF}$ at a reaction temperature of $120^{\circ} \mathrm{C}$. Figure 2 shows that radiochemical yields increased with higher concentrations, as expected, with a maximum radiochemical yield of about $65 \%$.

The use of higher concentrations at $120^{\circ} \mathrm{C}$ did not prevent the formation of by-product A but improved the relative yield of product ${ }^{18} \mathrm{~F}-12$; this result was caused by faster labeling than decomposition. The best results were achieved with a precursor concentration of $28.50 \mathrm{mmol} / \mathrm{L}$ at $120^{\circ} \mathrm{C}$.

The use of various temperatures $\left(100^{\circ} \mathrm{C}, 120^{\circ} \mathrm{C}\right.$, and $140^{\circ} \mathrm{C}$ ) resulted in almost the same radiochemical yield of ${ }^{18} \mathrm{~F}-12$, about $40 \%$, after about $5 \mathrm{~min}$ of reaction time. After $15 \mathrm{~min}$, however, the highest radiochemical yield of ${ }^{18} \mathrm{~F}-12$, $65 \%$, was achieved at $110^{\circ} \mathrm{C}$ (Fig. 2; Table 3).

As a result of these optimization studies, a precursor concentration of $14.25 \mathrm{mmol} / \mathrm{L}$ in $0.8 \mathrm{~mL}$ of DMF and a $\mathrm{TBAHCO}_{3}$ concentration of $25 \mathrm{mmol} / \mathrm{L}$ at $110^{\circ} \mathrm{C}$ resulted in a radiochemical yield of $\sim 55 \%$ of the desired product, (2S,5S)-tert-butyl-5-(4-benzyloxy-2-1 ${ }^{18} \mathrm{~F}$-fluoro-5-formylbenzyl)-2-tert-butyl-3-methyl-4-oxo-imidazolidine-1-carboxylate $\left({ }^{18} \mathrm{~F}-12\right)$, within $8 \mathrm{~min}$ of reaction time. Furthermore, under these conditions, the formation of the unwanted side product could be limited to a radiochemical yield of less than $13 \%$. The resulting radiolabeled product was purified by solid-phase extraction to remove the phase transfer catalyst and the polar solvent.
FIGURE 1. Radiosynthesis of ${ }^{18} \mathrm{~F}$-fluoro-L-DOPA ( $\left.{ }^{18} \mathrm{~F}-14\right)$ by Baeyer-Villiger oxidation of $18 \mathrm{~F}-12$ and subsequent acid hydrolysis. (i) mCPBA, $\mathrm{CHCl}_{3}$, $60^{\circ} \mathrm{C}, 20$ min. (ii) $\mathrm{HBr}(47 \%), 150^{\circ} \mathrm{C}, 30$ $\min$.

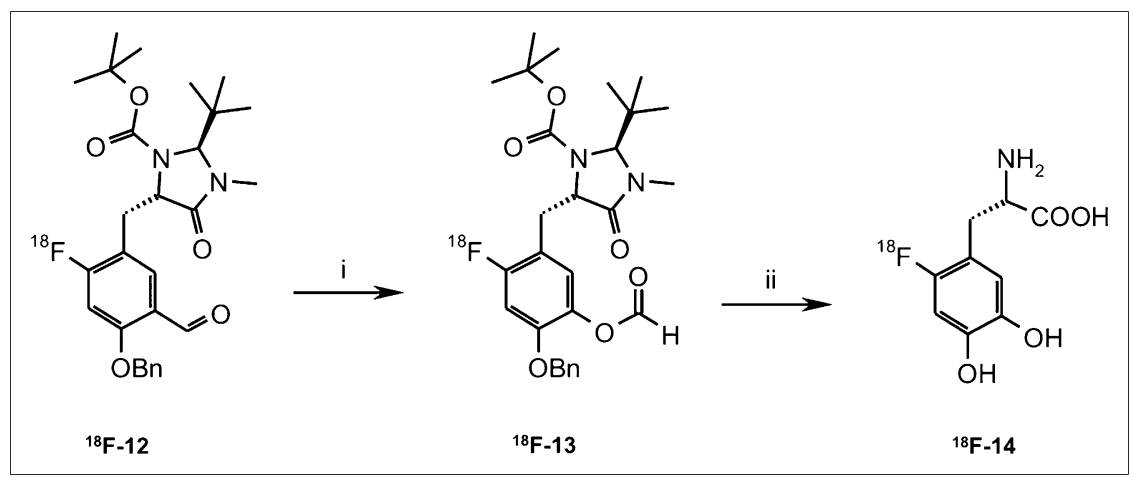


TABLE 1. Radiochemical Yields of Product ${ }^{18} \mathrm{~F}-12$ and By-Product A with Different Anion Activation

Phase Transfer Catalysts

\begin{tabular}{|c|c|c|}
\hline \multirow[b]{2}{*}{ Phase transfer catalyst } & \multicolumn{2}{|c|}{ Mean \pm SD (\%) } \\
\hline & ${ }^{18} \mathrm{~F}-12$ & By-product A \\
\hline $\mathrm{Cs}_{2} \mathrm{CO}_{3}$ & $9.5 \pm 2.1$ & \\
\hline (Kryptofix 2.2.2) ${ }_{2} \mathrm{CO}_{3}$ & $49.9 \pm 3.7$ & $30.75 \pm 6.2$ \\
\hline (Kryptofix 2.2.2) ${ }_{2} \mathrm{C}_{2} \mathrm{O}_{4} / \mathrm{CO}_{3}$ & $6.3 \pm 3.2$ & \\
\hline $\begin{array}{l}\text { Tetrabutylammonium } \\
\text { hydroxide }\end{array}$ & $2.3 \pm 0.4$ & $41.1 \pm 5.5$ \\
\hline $\mathrm{TBAHCO}_{3}$ & $47.6 \pm 10.3$ & $12.6 \pm 5.6$ \\
\hline
\end{tabular}

The following Baeyer-Villiger oxidation of the formyl group and subsequent acid hydrolysis were performed in a one-pot reaction. The oxidation step was achieved with mCPBA in chloroform within $20 \mathrm{~min}$ at $60^{\circ} \mathrm{C}$. A radiochemical yield of CA $(2 S, 5 S)$-tert-butyl 5-(4benzyloxy-2- ${ }^{18} \mathrm{~F}$-fluoro-5-(formyloxy)-benzyl)-2-tert-butyl3-methyl-4-oxoimidazolidine-1-carboxylate $\left({ }^{18} \mathrm{~F}-13\right)$ of about $80 \%$ was achieved (16). Next, the solvent was evaporated, $\mathrm{HBr}$ was added, and hydrolysis was performed at $150^{\circ} \mathrm{C}$ for $30 \mathrm{~min}$. Under these conditions, a total radiochemical yield of 6- ${ }^{18} \mathrm{~F}$-fluoro-L-DOPA of $22 \%$ was achieved within $105 \mathrm{~min}$; in a standard experiment starting with $370 \mathrm{MBq}$ of ${ }^{18} \mathrm{~F}$ fluoride, approximately $37 \mathrm{MBq}$ of $6-{ }^{18} \mathrm{~F}$-fluoro-L-DOPA were obtained after $105 \mathrm{~min}$. Product analysis with a chiral column (system D) revealed a high enantiomeric excess $(>96 \%)$ of the final product but also a radiochemical impurity to an extent of less than $3.3 \%$ of the radiochemical yield, probably from by-product $\mathrm{A}$, which was not separated by preparative HPLC (system C; supplemental materials). Thus, when this radiosynthesis procedure is scaled up on an automated system for routine production, the HPLC purification is subject to optimization.

\section{DISCUSSION}

The final radiosynthesis of $6-{ }^{18} \mathrm{~F}$-fluoro-L-DOPA involved the incorporation of ${ }^{18} \mathrm{~F}$-fluoride into the precursor

\section{TABLE 2. Radiochemical Yields of ${ }^{18} \mathrm{~F}-12$ and}

By-Products in Different Solvents

\begin{tabular}{|c|c|c|c|}
\hline \multirow[b]{2}{*}{ Solvent } & \multicolumn{3}{|c|}{ Mean \pm SD (\%) } \\
\hline & ${ }^{18} \mathrm{~F}-12$ & By-product $A$ & By-product B \\
\hline Acetonitrile* & $0.8 \pm 0.2$ & & \\
\hline DMAA & $26.6 \pm 3.5$ & $2.7 \pm 0.7$ & $13.4 \pm 2.0$ \\
\hline DMSO & $25.4 \pm 7.1$ & $6.4 \pm 2.9$ & $14.9 \pm 4.9$ \\
\hline DMF & $50.0 \pm 2.7$ & $9.3 \pm 2.8$ & \\
\hline $\begin{array}{c}{ }^{\star} 82^{\circ} \mathrm{C} . \\
{[12]=14.2} \\
\min (n=3), \text { ar }\end{array}$ & $\begin{array}{l}\mathrm{nmol} / \mathrm{L} \text {, TTE } \\
\text { sis by TLC }\end{array}$ & $\left.\mathrm{CO}_{3}\right]=25 \mathrm{r}$ & $\mathrm{ol} / \mathrm{L}, 120^{\circ} \mathrm{C}, 10$ \\
\hline
\end{tabular}

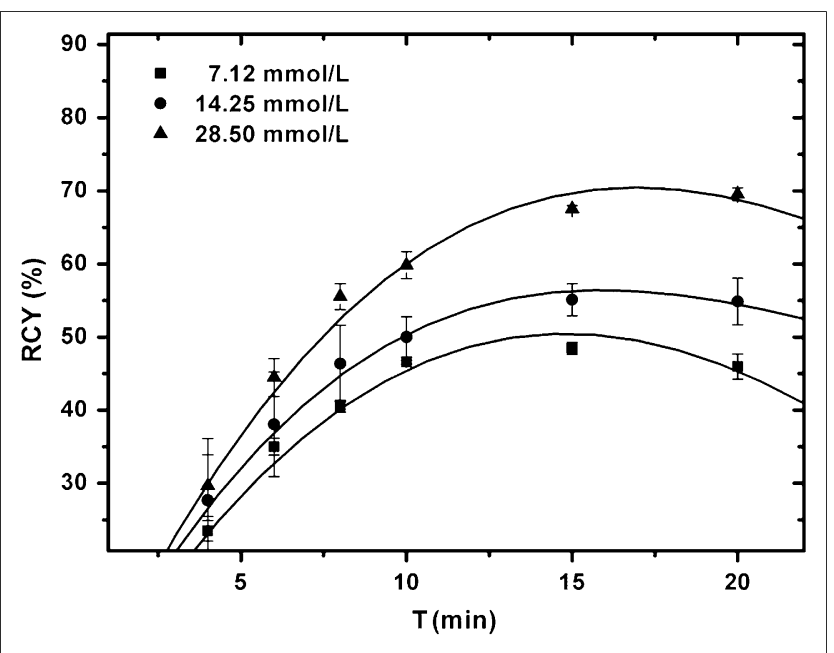

FIGURE 2. Radiochemical yield (RCY) of ${ }^{18} \mathrm{~F}-12$ as function of precursor concentration. [TBAHCO 3 ] $=25 \mathrm{mmol} / \mathrm{L}$, $800 \mu \mathrm{L}$ of DMF, $120^{\circ} \mathrm{C}(n=3)$, analyses by TLC. $\mathrm{T}=$ time.

(12), subsequent Baeyer-Villiger oxidation, and acid hydrolysis. The isotopic exchange reaction on compound 12 with NCA ${ }^{18}$ F-fluoride was the crucial step of this reaction sequence; therefore, different reaction conditions were examined. Most important was the choice of the anion activation system. The standard Kryptofix 2.2.2/potassium carbonate system, which is often used for nucleophilic aromatic ${ }^{18} \mathrm{~F}$-substitution reactions (22), led to unsatisfactory results. A further ${ }^{18} \mathrm{~F}$-labeled by-product (by-product A) was found in addition to the desired product $\left({ }^{18} \mathrm{~F}-12\right)$, limiting the radiochemical yield of the latter to $40 \%$. These findings reveal the sensitivity of the precursor to the basic ${ }^{18}$ F-labeling conditions, which are necessary to perform a nucleophilic ${ }^{18} \mathrm{~F}$ exchange. For reducing the basicity of the ${ }^{18}$ F-labeling solution, other anion activation systems were studied. In particular, the use of $\mathrm{TBAHCO}_{3}$ fulfilled the requirement of a high yield in the exchange reaction and a small amount of by-product A.

The choice of the solvent for the ${ }^{18} \mathrm{~F}$ exchange reaction had an influence on the formation of further by-products. The use

\section{TABLE 3. Radiochemical Yields of ${ }^{18} \mathrm{~F}-12$ and}

By-Product A with Variations in Temperature

\begin{tabular}{|c|c|c|}
\hline \multirow[b]{2}{*}{ Temperature $\left({ }^{\circ} \mathrm{C}\right)$} & \multicolumn{2}{|c|}{ Mean \pm SD (\%) } \\
\hline & ${ }^{18} \mathrm{~F}-12$ & By-product $A$ \\
\hline 100 & $43.5 \pm 2.3$ & $3.6 \pm 0.7$ \\
\hline 110 & $59.5 \pm 2.1$ & $11.5 \pm 1$ \\
\hline 120 & $50.0 \pm 2.7$ & $9.3 \pm 2.8$ \\
\hline 130 & $47.6 \pm 10.3$ & $12.6 \pm 5.6$ \\
\hline 140 & $39.4 \pm 16.4$ & $39.3 \pm 19.1$ \\
\hline $\begin{array}{r}{[\mathbf{1 2}]=14.25 \mathrm{~mm}} \\
(n=3), \text { analysis by }\end{array}$ & $\left.3 \mathrm{AHCO}_{3}\right]=2$ & /L, DMF, $10 \mathrm{~min}$ \\
\hline
\end{tabular}


of DMSO or DMAA led to a second by-product that was not found when DMF or acetonitrile was used. With acetonitrile, however, the yield was very low $(<1 \%)$, probably because of its low boiling point. Therefore, DMF proved to be an optimal solvent for the ${ }^{18} \mathrm{~F}$ displacement reaction.

Further, variations in temperature had a strong influence on decomposition and the formation of unwanted labeled byproduct A. At temperatures of $100^{\circ} \mathrm{C}, 120^{\circ} \mathrm{C}$, and $140^{\circ} \mathrm{C}$, nearly the same radiochemical yield of ${ }^{18} \mathrm{~F}-12$, about $40 \%$, was reached after about $5 \mathrm{~min}$ of reaction time. Unexpectedly, at $110^{\circ} \mathrm{C}$ the highest radiochemical yield of ${ }^{18} \mathrm{~F}-12$, $65 \%$, was achieved after $15 \mathrm{~min}$. When the temperature was increased to $140^{\circ} \mathrm{C}$, faster isotopic exchange could be observed; however, the decomposition reaction dominated after just $4 \mathrm{~min}$, leading to a radiochemical yield of about $40 \%$ for both ${ }^{18} \mathrm{~F}-12$ and by-product $\mathrm{A}$ (data not shown in detail). The formation of by-product $\mathrm{A}$ was about $10 \%$ at $110^{\circ} \mathrm{C}$ and was not influenced in the temperature range up to $130^{\circ} \mathrm{C}$ (Table 3 ). In summary, a reaction time of $8 \mathrm{~min}$ at a temperature of $110^{\circ} \mathrm{C}$ appeared to be most suitable for obtaining high radiochemical yields of ${ }^{18} \mathrm{~F}-12(\sim 65 \%)$ and relatively small amounts of radioactive by-product $\mathrm{A}(<10 \%)$.

Furthermore, at this temperature, the ratio of compound ${ }^{18}$ F-12 to the unknown side product was almost independent of the concentration of the precursor (12) in the range from 14.25 to $28.50 \mathrm{mmol} / \mathrm{L}$. Thus, the lower concentration, $14.25 \mathrm{mmol} / \mathrm{L}$, can be used for the ${ }^{18} \mathrm{~F}$-labeling step, facilitating the isolation of the product. Of course, when isotopic exchange is used for labeling, the lower concentration of the precursor increases the specific activity of the final product.

After the isotopic exchange reaction, it was necessary to remove the polar solvent and the nonreacted ${ }^{18} \mathrm{~F}$-fluoride from ${ }^{18} \mathrm{~F}-12$ to make the following reaction sequence possible. This step was achieved by intermediate solid-phase extraction.

The Baeyer-Villiger reaction was performed under the conditions described by Tierling et al. (16) with mCPBA in chloroform and was nearly quantitative. To avoid further separation after the oxidation step, we performed the subsequent hydrolysis and deprotection steps after the evaporation of chloroform by directly adding hydroiodic acid or $\mathrm{HBr}$. The reaction with hydroiodic acid was performed at $200^{\circ} \mathrm{C}$ for $30 \mathrm{~min}$. Under these previously reported conditions (13), radiochemical yields of $6-{ }^{18} \mathrm{~F}$-fluoro-L-DOPA $\left({ }^{18} \mathrm{~F}-14\right)$ of only $2 \%-5 \%$ were achieved. Changing to $\mathrm{HBr}$ under the same conditions led to almost the same results. However, decreasing the temperature to $170^{\circ} \mathrm{C}$ and $150^{\circ} \mathrm{C}$ increased the radiochemical yields to $5 \%-7 \%$ with hydroiodic acid and $22 \%$ with $\mathrm{HBr}$, respectively. The reason was probably the excess of mCPBA, which oxidized hydroiodic acid and $\mathrm{HBr}$ to elemental iodine and bromine, respectively, under the harsh conditions used. In addition, many side reactions reduced the radiochemical yield of $6^{6}{ }^{18} \mathrm{~F}$ fluoro-L-DOPA $\left({ }^{18} \mathrm{~F}-14\right)$. The use of lower temperatures could prevent these side reactions to some extent.

In the preparation of $6-{ }^{18} \mathrm{~F}$-fluoro-L-DOPA $\left({ }^{18} \mathrm{~F}-14\right)$, the maximum amount of carrier that can be expected from a starting quantity of precursor $\mathbf{1 2}$ of $11.5 \mu \mathrm{mol}$ is less than $2 \mathrm{mg}$. This amount is in the lower range for electrophilic methods, in which up to $15 \mathrm{mg}$ of 6-fluoro-L-DOPA are obtained and tolerated in tracer preparations for human injection (6). Although in production runs of electrophilic radiofluorine a specific activity of only about $0.3 \mathrm{GBq} / \mu \mathrm{mol}$ can be reached under optimal conditions (23), a value at least 5-fold higher can be attained with the isotopic exchange procedure, especially with the much larger amounts of ${ }^{18} \mathrm{~F}$ fluoride activity that can be generated in one irradiation batch.

The parameters of various methods for the synthesis of $6-{ }^{18} \mathrm{~F}$-fluoro-L-DOPA $\left({ }^{18} \mathrm{~F}-14\right)$ are summarized in Table 4. Compared with the electrophilic method, all nucleophilic procedures have more synthesis steps and thus are more time-consuming. The general advantage of nucleophilic ${ }^{18} \mathrm{~F}$ introduction is the possibility of a much higher starting activity. Until now, the nucleophilic approach of Lemaire et al. (14) has been the method of choice for obtaining $6-{ }^{18}$ F-fluoro-L-DOPA $\left({ }^{18} \mathrm{~F}-14\right)$ at the NCA level. Nevertheless, the number of steps involved prevents easy integration of the synthesis sequence into available standard commercial modules. The method of Tierling et al. (16) reduces the synthesis steps to only 3; however, the low enantiomeric excess of $6-{ }^{18} \mathrm{~F}$-fluoro-L-DOPA $\left({ }^{18} \mathrm{~F}-14\right)$ would demand an additional chiral HPLC separation. Based on the same ${ }^{18} \mathrm{~F}$ labeling concept, the new precursor described here (12) fulfils the requirements of efficient nucleophilic synthesis of $6-{ }^{18}$ F-fluoro-L-DOPA at a high enantiomeric excess.

\section{CONCLUSION}

The new precursor, $(2 S, 5 S)$-tert-butyl-5-(4-benzyloxy-2fluoro-5-formylbenzyl)-2-tert-butyl-3-methyl-4-oxoimidazolidine-1-carboxylate (12), enables the radiosynthesis of $6-{ }^{18}$ F-fluoro-L-DOPA by an isotopic exchange reaction with ${ }^{18}$ F-fluoride. After only 2 further radiosynthesis steps, namely, Baeyer-Villiger oxidation with mCPBA followed

\begin{tabular}{|c|c|c|c|c|}
\hline Method & Time (min) & Radiochemical yield (\%) & Enantiomeric excess (\%) & Amount (mg) \\
\hline de Vries et al. (9) & $<60$ & 33 & $>99$ & $\sim 10$ \\
\hline Lemaire et al. (14) & 90 & 20-30 & $>96$ & NCA \\
\hline Tierling et al. (16) & 70 & 16 & 70 & $<2$ \\
\hline Present study & 105 & 22 & $>96$ & $<2$ \\
\hline
\end{tabular}


by hydrolysis with $\mathrm{HBr}$, the desired L-isomer of CA $6-{ }^{18} \mathrm{~F}-$ fluoro-DOPA was isolated at an enantiomeric purity of more than $99 \%$. The complete preparation and isolation of CA $6-{ }^{18}$ F-fluoro-L-DOPA under the conditions optimized thus far resulted in a radiochemical yield of about $22 \%$ after a synthesis time of $105 \mathrm{~min}$. With other methods for the synthesis of $6-{ }^{18} \mathrm{~F}$-fluoro-L-DOPA starting from ${ }^{18} \mathrm{~F}$ fluoride, however, enantiomeric purity is insufficient or the necessary multistep syntheses are difficult to automate because of their complexity. Thus, the nucleophilic synthetic pathway to $6-{ }^{18}$ F-fluoro-L-DOPA described here not only is more efficient than known nucleophilic methods but also can be performed as a one-pot reaction. As a result, it is capable of being scaled up in existing automated synthesizer modules to offer reliable, large-scale production of 6- ${ }^{18}$ F-fluoro-L-DOPA.

\section{ACKNOWLEDGMENTS}

We thank Johnny Castillo Meléan for assistance, Kurt Hamacher and Marcus H. Holschbach (at INM-5, Forschungszentrum Jülich) for helpful discussions, Dr. Holschbach also for nuclear magnetic resonance measurements of organic compounds, and Sabine Willbold and Diana Hofmann (both at ZCH, Forschungszentrum Jülich) for assistance in the interpretation of the spectra and for recording high-resolution mass spectrometry.

\section{REFERENCES}

1. Garnett ES, Firnau G, Nahmias C. Dopamine visualized in the basal ganglia of living man. Nature. 1983;305:137-138.

2. Fischman AJ. Role of $\left[{ }^{18} \mathrm{~F}\right]$-dopa-PET imaging in assessing movement disorders. Radiol Clin North Am. 2005;43:93-106.

3. Groves AM, Win T, Haim SB, Ell PJ. Non- $\left[{ }^{18} \mathrm{~F}\right]$ FDG PET in clinical oncology. Lancet Oncol. 2007;8:822-830.

4. Seibyl JP, Chen W, Silverman DH. 3,4-Dihydroxy-6- $\left[{ }^{18} \mathrm{~F}\right]$ fluoro-L-phenylalanine positron emission tomography in patients with central motor disorders and in evaluation of brain and other tumors. Semin Nucl Med. 2007;37:440-450.

5. Jager PL, Chirakal R, Marriott CJ, Brouwers AH, Koopmans KP, Gulenchyn KY. 6-L- ${ }^{18} \mathrm{~F}$-fluorodihydroxyphenylalanine PET in neuroendocrine tumors: basic aspects and emerging clinical applications. J Nucl Med. 2008;49:573-586.

6. Fluorodopa $\left({ }^{18} \mathrm{~F}\right)$ (prepared by electrophilic substitution) injection. European Pharmacopoeia. 2008;6:990-992.
7. Namavari M, Bishop A, Satyamurthy N, Bida G, Barrio JR. Regioselective radiofluorodestannylation with $\left[{ }^{18} \mathrm{~F} \mathrm{~F}_{2}\right.$ and $\left[{ }^{18} \mathrm{~F}\right] \mathrm{CH}_{3} \mathrm{COOF}$ : a high yield synthesis of $\left[{ }^{18} \mathrm{~F}\right]$ fluoro-L-dopa. Appl Radiat Isot. 1992;43:989-996.

8. Dollé F, Demphel S, Hinnen F, Fournier D, Vaufrey F, Crouzel C. 6- $\left[{ }^{18}\right.$ F]fluoroL-DOPA by radiofluorodestannylation: a short and simple synthesis of a new labelling precursor. J Labelled Comp Radiopharm. 1998;41:105-114.

9. de Vries EFJ, Luurtsema G, Brüssermann M, Elsinga PH, Vaalburg W. Fully automated synthesis module for the high yield one-pot preparation of 6$\left[{ }^{18} \mathrm{~F}\right]$ fluoro-L-DOPA. Appl Radiat Isot. 1999;51:389-394.

10. Luxen A, Guillaume M, Melega WP, Pike VW, Solin O, Wagner R. Production of 6-[ ${ }^{18}$ F $]$ fluoro-L-dopa and its metabolism in vivo: a critical review. Nucl Med Biol. 1992;19:149-158.

11. Hess E, Sichler S, Kluge A, Coenen HH. Synthesis of $2-\left[{ }^{18} \mathrm{~F}\right]$ fluoro-L-tyrosine via regiospecific fluoro-de-stannylation. Appl Radiat Isot. 2002;57:185-191.

12. Lasne MC, Perrio C, Rouden J, et al. Chemistry of $\beta^{+}$-emitting compounds based on fluorine-18. Top Curr Chem. 2002;222:201-258.

13. Lemaire C, Guillaume M, Cantineau R, Christiaens L. No-carrier-added regioselective preparation of $6{ }^{18}$ F-fluoro-L-DOPA. J Nucl Med. 1990;31: 1247-1251.

14. Lemaire C, Gillet S, Guillout S, Plenevauax A, Aerts J, Luxen A. High selective synthesis of no-carrier-added 6-[ $\left.{ }^{18} \mathrm{~F}\right]$ fluoro-L-DOPA by phase transfer alkylation. Eur J Org Chem. 2004:2899-2904.

15. Schöllkopf U. Enantioselective synthesis of non-proteinogenic amino acids via metallated bis-lactim ethers of 2,5-diketopiperazines. Tetrahedron. 1983;39: 2085-2091.

16. Tierling T, Hamacher K, Coenen HH. A new nucleophilic asymmetric synthesis of 6-[ ${ }^{18}$ F]fluoro-DOPA. J Labelled Comp Radiopharm. 2001;44(suppl):S146S148.

17. Kuroda C, Ochi A, Nakane N, et al. Synthesis of a chiral precursor for no-carrieradded (NCA) PET tracer 6-[ ${ }^{18}$ F]fluoro-DOPA based on regio- and enantioselective alkylation of 2,4-bis(chloromethyl)-5-iodoanisole. Bull Chem Soc Jpn. 2000;73:417-422.

18. Seebach D, Dziadulewicz E, Behrendt L, Cantoreggi S, Fitzi R. Synthesis of nonproteinogenic $(R)$ - or $(S)$-amino acid analogues of phenylalanine, isotopically labelled and cyclic amino acids from tert.-butyl 2-tert. butyl-3methyl-4-oxo-1-imidazolidinecarboxylate (BOC-BMI). Liebigs Ann Chem. 1989;1215-1232.

19. Qaim SM, Clark JC, Crouzel C, et al. PET radionuclide production. In: Stöcklin G, Pike VW, eds. Radiopharmaceuticals for Positron Emission Tomography. Dordrecht, The Netherlands: Kluwer Academic Publishers; 1993:15-26.

20. Hamacher K, Hirschfelder T, Coenen HH. Electrochemical cell for separation of $\left[{ }^{18} \mathrm{~F}\right]$ fluoride from irradiated $\left[{ }^{18} \mathrm{O}\right]$ water and subsequent no-carrier-added nucleophilic fluorination. Appl Radiat Isot. 2002;56:519-523.

21. Hamacher K, Hamkens W. Remote controlled one-step production of ${ }^{18} \mathrm{~F}$ labeled butyrophenone neuroleptics exemplified by the synthesis of n.c.a. $\left[{ }^{18} \mathrm{~F}\right] \mathrm{N}$ methylspiperone. Appl Radiat Isot. 1995;46:911-916.

22. Coenen HH. Fluorine-18 labelling methods. In: Schubiger PA, Lehmann L, Friebe M, Yang DJ, eds. PET Chemistry: The Driving Force in Molecular Imaging. Berlin, Germany: Ernst Schering Research Foundation Workshop; 2007:15-50.

23. Hess E, Blessing G, Coenen HH, Qaim SM. Improved target system for production of high purity $\left[{ }^{18} \mathrm{~F}\right]$ fluorine via the ${ }^{18} \mathrm{O}(\mathrm{p}, \mathrm{n}){ }^{18} \mathrm{~F}$ reaction. Appl Radiat Isot. 2000;52:1431-1440. 